\title{
Institutional Profiles: Some Strategic Tools
}

Frans van Vught and Jeroen Huisman

\begin{abstract}
In this paper we argue that both internal and external pressures and conditions urge contemporary higher education institutions to carefully think through their institutional profiles positions in domestic and global higher education contexts. We subsequently analyse strategic positioning from the strategic management literature and offer four tools - mapping, multi-dimensional ranking, benchmarking and degree profiling - to assist higher education institutions in their profiling and positioning strategies.
\end{abstract}

Keywords: innovation policy, activity and performance profiles; strategy; autonomy; mapping; ranking; benchmarking; degree profiles.

\section{Introduction: the role of higher education in the knowledge economy}

There is an observable trend in many countries towards de-industrialisation and a corresponding government concern about how to promote innovation and technological change as a principal means of sustaining international competitiveness. Natural resources are no longer the dominant factor in economic growth. Goods, services, capital, labour, and knowledge move around the world with increasing speed and markets become increasingly interconnected and globalised. Generally speaking, it appears that globalisation leads to increasing national specialisation. This process of specialisation, which is amplified by scale and learning effects, creates a reallocation of production processes between countries and forces nations to look for their international comparative advantages. Given this situation, national governments try to identify and develop their specific strengths. They try to increase their location attractiveness for business firms; they try to attract mobile production factors; they develop their socio-cultural profiles; and they try to increase their innovation capacity. Many nations now seek to promote innovation as a key driver of economic growth. In particular Western industrialised nations try to find their comparative advantages in the production of knowledge-intensive goods and services. To better compete in a globalised economy they increasingly focus on knowledge, creativity and innovation, and on the role that higher education and research organisations 
could play as major contributors to the knowledge economy. National innovation policies have begun to shape and supersede traditional higher education and research policies. ${ }^{1}$

National innovation policies appear to take various forms. Dill and van Vught identified two broad categories of national innovation policy strategies. ${ }^{2}$ The first and largest category comprises what could be called prioritisation strategies. These policies are characterised by features such as foresight analyses in the science and technology sectors, priority allocation and concentration of resources, and quality assessments of research outputs. They reflect the notion of national planning (see for example Australia's research priority setting initiatives, Finland's technology and innovation policy with a key role for TEKES, and the Dutch Innovation Platform policy). The other category of innovation policies places an emphasis on market forces and competition. The policy characteristics of these competition strategies include an emphasis on competitive allocation of resources, encouraging entrepreneurial university behaviour, deregulating the higher education sector, and encouraging multiple sources of funding. The preeminent example of this strategy is the US federal science policy with its emphasis on a national marketplace of competing private and state universities, limited federal control, and the competitive allocation of funding by research funding agencies. But aspects of this type of competition strategy can also be found - to a greater or lesser degree - in e.g. Canada, Germany, Japan and the United Kingdom.

\section{Increasing institutional autonomy}

Higher education institutions increasingly have been granted more autonomy by their national governments. In the older days, governments largely decided on what higher education institutions should do. There were often detailed regulations regarding which programmes higher education institutions could offer and how these should be structured, detailed financial regulations determined how governmental budgets were to be spent, and the

${ }^{1}$ Marcus Balzat, An Economic Analysis of Innovation: Extending the Concept of National Innovation Systems (Cheltenham: Edward Elgar, 2006); Richard R Nelson, National Innovation Systems: A Comparative Analysis (Oxford: Oxford University Press, 1993); Organisation for Economic Co-operation and Development (OECD), Main Science and Technology Indicators (Paris: OECD, 2005).

${ }^{2}$ David D. Dill, and Frans A. van Vught, eds., National Innovation and the Academic Research Enterprise: Public Policy in Global Perspective (Baltimore: Johns Hopkins University Press, 2010). 
infrastructure of the higher education institutions (buildings, estate) were often owned by the government. ${ }^{3}$

Programmatic freedom has increased in many countries. Nowadays, governments often use lump sum funding with significant discretion for institutions to decide how and where to allocate the budgets. Human resource management policies have been devolved to higher education institutions, sometimes going hand in hand with a change of status of academic personnel from civil servant to employee. And, many higher education institutions are now responsible for their real estate.

This may look like a rosy picture of increasingly more scope for institutional strategies and profiling, but it is fair to state that governments have sometimes been hesitant to grant institutional autonomy in all areas. ${ }^{4}$ Moreover, governments have often exchanged a priori evaluation (through regulations) with ex post evaluations. ${ }^{5}$ That said, comparing the current levels of institutional autonomy with the situation a few decades ago, there is arguably much more scope for strategic choice by higher education institutions.

However, it is clear that governments and other stakeholders want something back in return for this increased autonomy. The crucial roles higher institutions can play with respect to national innovation policies are turning them into an object of policy attention. External stakeholders (including potential new students and business \& industry) ask for more transparency and accountability, and increasingly confront higher education institutions with questions about their relevance and effectiveness in terms of national innovation.

\section{Challenges for higher education institutions}

Obviously the changing context described above has major impacts on higher education institutions. We present some of these challenges under

${ }^{3}$ See e.g. Leo Goedegebuure et al., eds., Higher Education Policy. An International Comparative Perspective (Oxford: Pergamon, 1994).

${ }^{4}$ Thomas Estermann, and Terhi Nokkala, University Autonomy in Europe I (Brussels: EUA, 2009); Åse Gornitzka, and Peter Maassen, "Hybrid Steering Approaches with Respect to European Higher Education.” Higher Education Policy 13, no. 3 (2000): 267-68; Guy Neave, and Frans A. van Vught, eds., Prometheus Bound. The Changing Relationship between Government and Higher Education in Western Europe (Oxford: Pergamon, 1991).

5 Guy Neave, "The Evaluative State Reconsidered," European Journal of Education 33, no. 3 (1998): 265-84; Guy Neave, The Evaluative State, Institutional Autonomy and ReEngineering Higher Education in Western Europe. The Prince and His Pleasure (Basingstoke: Palgrave Macmillan, 2012). 
three headings: mission overload, global research competition, and system diversity. The overarching theme of these challenges is the imperative for higher education institutions to rethink their role in the higher education landscape and to consider and develop what we will term 'institutional profiles'. Institutional profiles are to be understood as key characteristics of the mission, activities and performances of higher education institutions. Institutional profiles can be divided into 'activity profiles' and 'performance profiles'. Activity profiles describe what higher education institutions do, illustrating their activities. Performance profiles are about how good higher education institutions are in performing their activities.

\section{Mission overload}

Higher education institutions are increasingly facing rising expectations and an expanding set of challenges. They are expected to address the world's major problems - e.g. those related to our natural environment; the settlement and movement of people; pandemics; poverty; terrorism etc. Worldwide there is widespread expect ation that universities and other institutions should research an increasingly broad range of problems in an ever-growing holistic fashion and at an accelerated pace (see e.g. the European Commission's Horizon 2020 programme). As our societies become more knowledgeable, universities and research institutions come under increasing pressure to expand transfer of knowledge and apply new knowledge in order to solve the problems confronting the world.

In addition, these expectations are becoming increasingly diversified. Higher education institutions are expected to produce the knowledge and human capital that meet the needs of the modern knowledge society, play a central role in innovation processes, contribute to regional development, increase social inclusion and contribute to the resolution of global problems. Governments tend to translate these multiple expectations into roles and responsibilities, often backed by earmarked funding or with conditions attached to general budgets. Higher education institutions themselves tend to take on a wider set of activities, partly through political and social pressure and partly in response to market opportunities.

The result can be an accumulation of mission elements, leading to the risk of mission overload. Higher education institutions increasingly face the challenge to strategically consider their basic focus and portfolios. 


\section{Global research competition}

On a worldwide scale, company labs are increasingly putting an end to their basic research activities. Companies are concentrating on short-term results, while adopting a strategic global approach to more basic research increasingly reliant on offshore partnerships, academic collaboration and outsourcing to established networks of scientific expertise.

National innovation policies, with their emphasis on the application of new knowledge, serve to encourage universities and other research organisations to participate in these new global research networks. There appears to be increasing competition between nations to make themselves attractive to footloose corporate $R \& D$ investments. In their innovation policies nations aim to prioritise and concentrate their own research expenditures to achieve competitive scale and quality. In addition, nations increasingly show a willingness to coordinate their own research investments with large international research budgets, like those of the European Union.

As a result, universities and research institutions are confronted with the challenge of selecting and investing in those research fields in which they can compete on a global scale. This often requires risky investments in research teams, major facilities and equipment. The current global research competition drives universities towards new forms of strategic management forcing them to make major strategic choices regarding their research portfolios and to marshal their resources effectively and efficiently.

\section{Higher education system diversity}

In the context of innovation, higher education institutions are not only stimulated to focus on relevant knowledge production. They are also urged to increase participation rates and particularly the supply of well-trained 'knowledge workers' in prioritised sectors in order to support the creation of effective human capital, needed for a successful implementation of the national innovation policy.

Globalisation and the focus on innovation in many countries appear to trigger diversification policies in higher education. The urge to diversify both in terms of programmes offered and in terms of institutional profiles - appears to be a key knock-on effect of national innovation strategies in many higher education systems. The literature suggests two key factors assumed to have an impact on the level of diversity: governmental regulation 
and market competition, ${ }^{6}$ both affecting diversity in different ways . Governmental regulation (for instance the creation or maintenance of a binary system) is thought to limit the scope for higher education institutions to develop their own profiles and so can be expected to limit diversity. At the same time, regulation is sometimes deemed a 'necessary evil' to forestall academic drift (and consequently homogenisation). Market competition is thought to offer leeway for institutional profiling and therefore is assumed to lead to higher levels of diversity. But markets also lure organisations into mimicking successful players and hence also foster homogenisation. ${ }^{7}$

It has been suggested that the strategic positioning of individual higher education institutions, and particularly their ability to occupy favourable niche positions, may play an important role in terms of the overall level of diversity among higher education systems. ${ }^{8}$ Both governments and higher education institutions themselves increasingly focus on the strategic development of a widening range of teaching and learning programmes and specific institutional educational portfolio's.

\section{Strategic challenges, the need for profiling}

Bringing the consequences together, the need for institutional profiling becomes evident. First, because of the increasing expectations and challenges, higher education institutions need to reassess and clarify their missions, goals and priorities, carefully defining their institutional profiles. In addition, the increasing global competitiveness strengthens the need for profiling. Strategic research management - including a deliberation with whom to compete AND with whom to collaborate - is therefore one of the most important aspects of modern higher education leadership. Modern research management implies a clear view of an institution's research strengths and weaknesses in a competitive

${ }^{6}$ Jeroen Huisman, and Frans A. van Vught, "Diversity in European Higher Education: Historical Trends and Current Policies," in Mapping the Higher Education Landscape. Towards a European Classification of Higher Education, edited by Frans A. van Vught. 17-37 (Dordrecht: Kluwer, 2009); Lynn Meek, Leo C J Goedegebuure, and Jeroen Huisman, "Editorial: Diversity, Differentiation and the Market," Higher Education Policy 13, no. 1 (2000): 1-6.

${ }^{7}$ See also Jeroen Huisman, Lynn Meek, and Fiona Q. Wood, "Institutional Diversity in Higher Education: A Cross-National and Longitudinal Analysis," Higher Education Quarterly 61, no. 4 (2007): 563-77.

8 Tatiana Fumasoli, and Jeroen Huisman, "Strategic Agency and System Diversity: Conceptualizing Institutional Positioning in Higher Education," Minerva 51, no. 2 (2013): 15569; Frans A. van Vught, "Mission Diversity and Reputation in Higher Education," Higher Education Policy 21, no. 1 (2008): 151-74. 
global research market and the courage to select and develop a set of research field priorities as a major defining part of the institutional profile. Finally, the need for profiling furthermore stems from governments' imperatives regarding their national higher education systems. Governments often seek an increasing diversity of the overall sets of higher education programmes and urge higher education institutions to contribute to this diversification.

All these factors force higher education institutions to carefully consider their strategic choices regarding their activities and performances. In other words, they are incentives for higher education institutions to sharpen their institutional profiles and to develop them as key strategic tools in positioning their institution in both their national higher education system and international context.

\section{Institutional profiles and strategic choice: a theoretical base}

Institutional profiles display what the institution does, how good it is at it and how it compares to other institutions. As was suggested earlier, institutional profiles can be divided into activity profiles and performance profiles. Activity profiles describe the actual activities of an institution in terms of focus, volume, priorities, etc. Activity profiles are descriptive and map the set of activities that defines the various tasks that an institution sets for itself. Performance profiles are evaluative, they show how well an institution performs these tasks, and hence imply a judgement in terms of the output and impact of an institution's activities.

Generally speaking, an institution's profile reflects the dimensions of its mission. These can be the well-known basic dimensions of teaching \& learning, research and knowledge exchange or transfer. But an institution may wish to emphasise other dimensions as equally important aspects of its mission, such as international orientation or regional engagement.

By providing information about the activities and/or performance of a higher education institution in terms of the dimensions of its mission, institutional profiles serve as transparency instruments allowing both internal and external actors (including students, funders, governments) to get to know the institution and to assess it as a potential fit with their needs and priorities.

In order to learn how to grasp the topic of institutional profiles we turn - building on earlier work ${ }^{9}$ - to the corporate sector literature. Not surprisingly, there are different perspectives on organisational profiling in

\footnotetext{
9 Fumasoli and Huisman, "Strategic Agency and System Diversity".
} 
that corporate sector literature, but for our purpose, a distinction between inside-out and outside-in perspectives is deemed relevant.

Outside-in perspectives argue that environmental factors determine to a large extent the scope for organisational action. The population ecology approach would be an extreme version of this, arguing that environments select organisations and individual organisations do not have or limited strategic intent. ${ }^{10}$ Insofar as organisations have strategic intent, this is largely overshadowed by the powers of environmental forces determining populations' growth rates and organisations' survival rates. Also new institutional theory stresses the role of the environment: the environment 'forces' organisations to comply with institutional norms and values. ${ }^{11} \mathrm{~A}$ similar emphasis on environments (markets) can be found in Porter's work. ${ }^{12}$ He urges businesses to focus on competition, achieving strong market positions and creating a competitive advantage. The market position is key in the outside-in approach and 'only' then resources are considered.

At the other end of the spectrum, we see perspectives that stress much more the role of internal capabilities, competencies and resources. The resource-based view, for instance, argues that the business strength should be taken as a point of departure. ${ }^{13}$ Businesses should focus on developing difficult-to-imitate products or services and subsequently suitable markets should be found.

For other perspectives it is sometimes difficult to locate these on the inside-out versus outside-in dimension. Some scholars take an intermediate stance in the debate and argue that both the environment and internal capabilities need to be taken into account. For instance, the resource dependency approaches would stress the overwhelming importance of resources in the environment that need to be acquired to survive. ${ }^{14}$ But at the same time, it argues that the internal perceptions, deliberations, negotiations and coalition formation play an important role. These internal forces are not explicitly labelled as capabilities or competencies by Pfeffer and Salancik

${ }^{10}$ Michael Hannan, and John Freeman, "The Population Ecology of Organizations," American Journal of Sociology 82, no. 5 (1977): 929-64.

${ }^{11}$ Paul J. DiMaggio, and Walter W. Powell, "The Iron Cage Revisited: Institutional Isomorphism and Collective Rationality in Organizational Fields," American Sociological Review 48 (1983): 147-60.

${ }_{12}$ Michael E. Porter, Competitive Advantage: Creating and Sustaining Superior Performance (New York: Free Press, 1985).

13 Jay B. Barney, "Firm Resources and Competitive Sustained Advantage," Journal of Management 17, no. 1 (1991): 99-120.

${ }^{14}$ Jeffrey Pfeffer, and Gerald R. Salancik, The External Control of Organizations. A Resource Dependence Perspective (New York: Harper \& Row, 1978). 
(1978) but can be seen as such if one were to compare their perspective with e.g. the resource-based view. Likewise, relatively recent developments in institutional theory argue for more attention to the role of agency in institutional change. ${ }^{15}$ These authors argue that powerful agents in organisational fields can affect the environment and institutional rules and, consequently, create space for other types of organisations that are able to acquire significant levels of legitimacy. In other words, although environments put pressure on organisations to conform to institutional rules, there is also scope for entrepreneurial and strategic action to deviate from existing rules.

The jury is still out whether inside-out and outside-in perspectives can or should be combined. ${ }^{16}$ For the purpose of this paper, we think it is sound to posit the following, quoting Fumasoli and Huisman:

... higher education institutions respond to demands, opportunities and threats offered by the environment by displaying different degrees of agency: from reacting and adapting, to intervening dynamically to modify the context in which they are embedded. Organisational positioning is the result of both organisational action and environmental determination. Positioning is partly avoiding competition by carving out a sustainable niche in which it offers a mix of services, and partly competing on selected activities in different markets (for students, for staff, for funds) with a subset of institutions in the higher education system. ${ }^{17}$

Now that we have explored the potential theoretical foundations of institutional profiles, let us turn to the question how these institutional profiles can be developed in practice. In the next section, four different tools are offered.

\section{Institutional profiles: operational tools}

In this section we discuss a set of practical and operational instruments that allow both internal and external higher education stakeholders to present and analyse institutional profiles.

15 Royston Greenwood, and Roy Suddaby, "Institutional Entrepreneurship in Mature Fields: The Big Five Accounting Firms," Academy of Management Journal 49, no. 1 (2006): 27-48; Pursey Heugens and Michel Lander, "Structure! Agency! (and Other Quarrels): A Meta-Analysis of Institutional Theories of Organization," Academy of Management Journal 52, no. 1 (2009): 61-85; Steve Maguire, Cynthia Hardy, and Thomas Lawrence, "Institutional Entrepreneurship in Emerging Fields: Hiv/Aids Treatment Advocacy in Canada," Academy of Management Journal 47, no. 5 (2004): 657-79.

${ }^{16}$ See e.g. Bob de Wit, and Ron Meyer, Strategy: Process, Content, Context. An International Perspective 4th ed. (Andover: Cengage Learning EMEA, 2010), chapter 5, for a very good overview of the debate.

${ }^{17}$ Fumasoli and Huisman, Strategic Agency and System Diversity. 


\section{Mapping}

'Mapping' is an interesting way to present institutional activity profiles. When a profile is 'mapped', the focus is on describing its various activities. Rather than taking a specific ideal type as the base for comparing a variety of profiles (as is the case in a number of current rankings), a mapping exercise begins by making the range of profiles visible and transparent and only focuses at comparing institutions with similar (or largely similar) profiles. In addition, instead of comparing all possible profiles, this approach compares apples with apples and oranges with oranges. It aims to portray the specific activity profiles of comparable individual institutions in a number of profile dimensions.

The European U-Map tool has been developed to allow the creation and analysis of these activity profiles, offering snapshots of an institution's activities on different dimensions. ${ }^{18}$ U-Map can be accessed online and offers two tools (the Profile Finder and the Profile Viewer) that allow stakeholders to analyse institutional profiles and carry out specific comparative studies (benchmarking). The six dimensions of U-Map are: teaching \& learning; student profile; research involvement; regional engagement; involvement in knowledge exchange; and international orientation. For each dimension, sets of indicators have been developed, with institutional profiles comprising the scores on all or a certain number of the dimensions. A profile reflects those areas where an institution is active and indicates the intensity of activities per dimension.

Of course it is up to the higher education institutions to choose their own profiles but once this is done, a mapping exercise allows for effective and useful benchmarking processes (see below). In addition, a university that knows its activity profile well and knows which counterpart institutions have similar profiles is able to identify to external stakeholders the role and position it occupies within its higher education system and how it wants to be held accountable.

\section{Multidimensional ranking}

Multidimensional ranking is a transparency tools that allows the presentation and analysis of institutional performance profiles. Multidimensional ranking is very different from the well-known and highly visible

${ }^{18}$ Frans A. van Vught, ed., Mapping the Higher Education Landscape: Towards a European Classification of Higher Education (Dordrecht: Kluwer, 2009). 
global university rankings. ${ }^{19}$ Multidimensional ranking implies an approach to comparing institutional performance profiles based on a number of crucial so-called 'design principles'. Starting from the fundamental epistemological point of view that 'objective rankings' cannot be developed, multidimensional ranking is user-driven (users construct their own rankings based on their selection of dimensions and indicators), multidimensional (reflecting a multiplicity of functions of higher education institutions), focused on comparable institutions only (comparing profiles that are sufficiently similar), multi-level (comparing performance at an institutional and at a 'field' level) and methodologically sound (avoiding composite indicators, and taking into account disciplinary, language and cultural differences).

The U-Multirank tool) ${ }^{20}$ which is based on these design principles, enables its users to identify comparable institutions and programmes, to create both institutional and field level performance profiles of individual institutions, and to undertake comparative performance analyses of institutions and programmes. U-Multirank consists of five performance dimensions (teaching and learning, research, knowledge transfer, international orientation, regional engagement) and a range of indicators for each dimension from which the users can choose.

U-Multirank provides its users with an on-line functionality to create two general types of rankings:

- focused institutional rankings: rankings on the indicators of a (selection of) the five performance dimensions at the level of an institution as a whole.

- field-based rankings: rankings on the indicators of a (selection of) performance dimensions in a specific (disciplinary) field.

\section{Benchmarking}

Benchmarking can be seen as a 'logical' follow-up to mapping and multidimensional ranking, but benchmarking can take place independently from the phase of an extensive search for comparable partners. Burquel and van Vught present benchmarking as an exercise going beyond current quality approaches and define it as “... the process of self-evaluation and

${ }^{19}$ For a comprehensive overview of the criticism of current rankings, see Frans A. van Vught, and Frank Ziegele, eds., Multidimensional Ranking. The Design and Development of U-Multirank. (Dordrecht: Springer, 2012.)

${ }^{20}$ van Vught and Ziegele, Multidimensional Ranking. 
self-improvement through the systematic and collaborative comparison of practice and performance with similar organisations in order to identify strengths and weaknesses, to learn how to adapt and improve organisational processes". ${ }^{21}$ The basic idea is that benchmarking is a self-analysis and quality-enhancing tool. Through a systematic comparison of central institutional processes with other higher education institutions, an organisation will gain insight in potential improvements of its performance. A crucial difference with other quality instruments is that the organisations involved in the benchmarking process set the performance targets themselves, i.e. they are not forced up by external quality assurance agencies. This arguably leads to a stronger sense of commitment and engagement with the improvement process. Furthermore, it has other added value for it will likely lead to strategic decision-making based on systematic gathering of relevant data. ${ }^{22}$

Van Vught and others - on the basis of a project funded by the European Commission - report on experiences with benchmarking processes. ${ }^{23}$ They argue that the following format may be helpful as a generic template for benchmarking. That format consists of four steps. The first one entails defining priorities, targets, criteria, indicators and benchmarks for all institutions involved in the process. The second step involves gathering the relevant data to 'score' each of the institutions on all benchmark indicators. Third, an in-depth analysis should take place of the processes behind the scores followed by developing relevant action plans for improvement. The last stage relates to the implementation of the action plan and concluding the benchmarking cycle. Obviously, the benchmarking cycle can - for those institutions that think this is relevant and worthwhile - be repeated. Alternatively, an institution performing at satisfactory levels can decide to focus on other facets of its functioning.

In benchmarking processes, (elements of) institutional activity profiles or institutional performance profiles can form an effective starting point. Using a 'mapping' tool, which will produce activity profiles, or a multidimensional ranking tool, which will offer performance profiles, allows actors involved in a benchmarking process to compare activities and/or performances of a set of higher education institutions. Based on jointly

${ }^{21}$ Nadine Burquel, and Frans van Vught, "Benchmarking in European Higher Education: A Step Beyond Current Quality Models," Tertiary Education and Management 16, no. 3 (2010): 249.

22 Ibid., 244.

${ }^{23}$ Frans A. van Vught et al., A University Benchmarking Handbook. Benchmarking in European Higher Education (Brussels: ESMU, 2010). 
undertaken comparative analyses, a focused quality improvement process can then be designed and implemented.

\section{Degree profiles}

A particularly relevant approach for teaching and learning is to be found in the idea of degree profiles, developed in the context of the Tuning project. Degree profiles can be conceived of as a potentially fruitful elaboration of the 'teaching and learning' dimension of the mapping and multidimensional tools mentioned before. In both U-Map and U-Multirank this dimension is being distinguished and operationalised by offering sets of indicators. Degree profiles capture the 'essence' of specific study programmes and hence they offer the possibility to link these to the indicators to be applied in the other transparency tools.

Lokhoff et al. suggest that degree profiles should be designed to summarise the essential information about a specific study programme. It "locates the programme in the academic map of disciplines and thematic studies". ${ }^{24}$ The profile specifies subject areas and the competences and learning outcomes that graduates will have achieved upon completion of the degree. It does not only function as a tool of transparency - allowing for international comparisons of degree contents - but also allows for differentiation. Higher education institutions can include specialisations, strong points, etc. in their degree profiles, which could be an add-on to the general institutional profile.

Degree profiles are powerful reference points for various stakeholders. Students and instructors can use them to discuss, analyse and administer learning programmes, courses, assignments and assessments. Institutions can make use of them in curriculum development and degree planning. Quality assurance agencies and accrediting organisations can apply them when addressing the quality of programmes and institutions.

In terms of institutional profiling, degree profiles offer a base for higher education institutions on which they can build and present their own teaching and learning activities and performances. As such they can be part of the broader profiling tools such as U-Map and U-Multirank and assist higher education institutions to focus on transparency and quality in their educational functions.

${ }^{24}$ Jenneke Lokhoff et al., eds., A Tuning Guide to Formulating Degree Programme Profiles. Including Programme Competences and Programme Learning Outcomes (Bilbao: Universidad de Deusto, 2010): 15. 


\section{Conclusions}

The analysis presented above makes clear that higher education institutions can and must make strategic choices. For higher education institutions it is of utmost importance to carefully think through which position they want to take in the national and global higher education landscapes and to consider whether these positions are sustainable. Finding, analysing and communicating their profiles has become a major strategic challenge for any higher education institution.

Theoretically both the outside-in perspectives (focusing on the challenges that arise from global and national markets) and inside-out perspectives (focusing on strengths, competencies and capabilities) will be helpful to guide higher education institutions in these processes. In operational terms we have offered a set of tools that can assist higher education institutions to present, compare and analyse their profiles.

If higher education institutions are able to position themselves and develop sound and robust profiles, governments will be better able to answer questions like: do we have the best set of institutional profiles in the context of the global competition for talent and knowledge? Do we have the best range of profiles in order to further develop our knowledge economy? Do we have the best possible spread and critical mass of research units and infrastructures? In addition, by studying these profiles other stakeholders will be able to be better informed about the various ways different higher education institutions respond to their needs and interests. Finally for higher education institutions themselves institutional profiles offer fruitful and effective ways to better understand, analyse and position themselves in the rapidly changing contexts they are confronted with.

\section{Bibliography}

Balzat, Marcus. An Economic Analysis of Innovation: Extending the Concept of National Innovation Systems. Cheltenham: Edward Elgar, 2006.

Barney, Jay B. "Firm Resources and Competitive Sustained Advantage." Journal of Management 17, no. 1 (1991): 99-120.

Burquel, Nadine, and Frans van Vught. "Benchmarking in European Higher Education: A Step Beyond Current Quality Models." Tertiary Education and Management 16, no. 3 (2010): 243-55.

de Wit, Bob, and Ron Meyer. Strategy: Process, Content, Context. An International

Perspective 4th ed. Andover: Cengage Learning EMEA, 2010

Dill, David D., and Frans A. van Vught, eds. National Innovation and the Academic Research Enterprise: Public Policy in Global Perspective. Baltimore: Johns Hopkins University Press, 2010. 
DiMaggio, Paul J., and Walter W. Powell. "The Iron Cage Revisited: Institutional Isomorphism and Collective Rationality in Organizational Fields." American Sociological Review 48 (1983): 147-60.

Estermann, Thomas, and Terhi Nokkala. University Autonomy in Europe I. Brussels: EUA, 2009.

Fumasoli, Tatiana, and Jeroen Huisman. "Strategic Agency and System Diversity: Conceptualizing Institutional Positioning in Higher Education." Minerva 51, no. 2 (2013): 155-69.

Goedegebuure, Leo, Frans Kaiser, Peter A. M. Maassen, V. Lynn Meek, Frans A. van Vught, and Egbert de Weert, eds. Higher Education Policy. An International Comparative Perspective. Oxford: Pergamon, 1994.

Gornitzka, Åse , and Peter Maassen. «Hybrid Steering Approaches with Respect to European Higher Education.» Higher Education Policy 13, no. 3 (2000): 267-68.

Greenwood, Royston, and Roy Suddaby. "Institutional Entrepreneurship in Mature Fields: The Big Five Accounting Firms." Academy of Management Journal 49, no. 1 (2006): 27-48.

Hannan, Michael T., and John Freeman. "The Population Ecology of Organizations." American Journal of Sociology 82, no. 5 (1977): 929-64.

Heugens, Pursey P. M. A. R., and Michel W. Lander. "Structure! Agency! (and Other Quarrels): A Meta-Analysis of Institutional Theories of Organization.” Academy of Management Journal 52, no. 1 (2009): 61-85.

Huisman, Jeroen, V. Lynn Meek, and Fiona Q. Wood. "Institutional Diversity in Higher Education: A Cross-National and Longitudinal Analysis." Higher Education Quarterly 61, no. 4 (2007): 563-77.

Huisman, Jeroen , and Frans A. van Vught. "Diversity in European Higher Education: Historical Trends and Current Policies." In Mapping the Higher Education Landscape. Towards a European Classification of Higher Education, edited by Frans A. van Vught. 17-37. Dordrecht: Kluwer, 2009.

Lokhoff, Jenneke, Bas Wegewijs, Katja Durkin, Robert Wagenaar, Julia González, Ann Katherine Isaacs, Luigi F. Donà dalle Rose, and Mary Gobbi, eds. A Tuning Guide to Formulating Degree Programme Profiles. Including Programme Competences and Programme Learning Outcomes. Bilbao: Universidad de Deusto, 2010.

Maguire, Steve, Cynthia Hardy, and Thomas B. Lawrence. "Institutional Entrepreneurship in Emerging Fields: HIV/AIDS Treatment Advocacy in Canada." Academy of Management Journal 47, no. 5 (2004): 657-79.

Meek, V. Lynn, Leo C J Goedegebuure, and Jeroen Huisman. "Editorial: Diversity, Differentiation and the Market." Higher Education Policy 13, no. 1 (2000): 1-6.

Neave, Guy. "The Evaluative State Reconsidered." European Journal of Education 33, no. 3 (1998): 265-84.

- The Evaluative State, Institutional Autonomy and Re-Engineering Higher Education in Western Europe. The Prince and His Pleasure. Basingstoke: Palgrave Macmillan, 2012. 
Neave, Guy, and Frans A. van Vught, eds. Prometheus Bound. The Changing Relationship between Government and Higher Education in Western Europe. Oxford: Pergamon, 1991.

Nelson, Richard R. National Innovation Systems: A Comparative Analysis. Oxford: Oxford University Press., 1993.

Organisation for Economic Co-operation and Development (OECD). Main Science and Technology Indicators. Paris: OECD, 2005.

Pfeffer, Jeffrey, and Gerald R. Salancik. The External Control of Organizations. A Resource Dependence Perspective. New York: Harper \& Row, 1978.

Porter, Michael E. Competitive Advantage: Creating and Sustaining Superior Performance. New York: Free Press, 1985.

van Vught, Frans A., ed. Mapping the Higher Education Landscape: Towards a European Classification of Higher Education. Dordrecht: Kluwer, 2009.

- "Mission Diversity and Reputation in Higher Education." Higher Education Policy 21, no. 1 (2008): 151-74.

van Vught, Frans A., Anja Balanskat, Paul Benneworth, Paulo Botas, Uwe Brandenburg, Nadine Burquel, Harry de Boer, et al. A University Benchmarking Handbook. Benchmarking in European Higher Education. Brussels: ESMU, 2010.

van Vught, Frans A., and Frank Ziegele, eds. Multidimensional Ranking. The Design and Development of U-Multirank. Dordrecht: Springer, 2012. 